\title{
Main Inventory Management Elements on Reducing Storage Cost
}

\author{
Entsar Kouni A Alhaj Mohamed \\ Department of Accounting, Zawia University \\ Zawia City, Libya \\ Email: zhrkb [AT] yahoo.com
}

\begin{abstract}
Industrial sector in Libya needs modernization process that will upgrade the level of its local industrial Companies, and allowing them to achieve the highest possible level to compete globally. Although there is no sufficient accounting information system in place to calculate the considerably high storage cost, this study pointed out some factors that might affect it. This study, based on an academic and theoretical literatures regarding the factors that believed to affect the process of reducing storage cost as well as conducting some statistical analyses to the study sample which are the workers and managers in mixing and mobilization factory in Zawia. The results shed the light on the number of indications, which can be generalizable to future research, for instance; choosing right suppliers, using Kanban, and purchasing contracts.
\end{abstract}

Keywords--- IM: inventory management, TS: transportation strategy, Kanban; card program to control materials

\section{INTRODUCTION}

Nowadays, Managing the inventory has become a special issue, because of its great importance, especially for the managers, who must decide how much to hold and how to administer the rest of the logistics system more creatively, in order to ensure that the customer service does not suffer as a result of lowering the inventory levels (Apod, 2001; Josep, 2009; Krisztina \& Matyusz, 2010).

Neglecting the importance of the inventory can lead to the closing down of the company, especially if the factors of production are not well-managed in order to meet the customers' needs, the company will grind to the halt. The stock of an item must be reasonable, meaning that it should not be too much or too little, the company should be in a position to meet the customer's demand in terms of quantity and quality (Alan, 2008).

The inventory management requires a particular attention in order to meet customer satisfaction and reduce storage cost. It's not easy to control or maintain any kind of inventory at a level where can prevent any problem as a result of an inventory shortage. This makes this problem very important as all companies or factories must have inventories in their warehouses (Mahmod, 2011; Monden, 1983; Vedran, Hameri \& Weiss, 2009).

The inventory has been defined in many ways. As indicated in the literature, four definitions have been chosen that seems to be more appropriate to the topic of research. Mahmod (2011) has defined the inventories as stockpiles of raw materials, suppliers' components, work in process and finished goods that appear at numerous points throughout a firm's production, and logistics channels. According to Chase et al (2004), inventory is the stock of any items or resource used in an organization. Also, Robert \& Donhauser (2009) implied that the inventory system is a set of policies and controls that monitor levels of the inventory and determines what level should be maintained, when the stock should be replenished and how big the order should be . Vedran et al., (2009) defined inventory or stock as a stored accumulation of material resources in the transformation system, therefore, manufacturing companies will hold stock of material, a tax office will hold stock of information, and a theme park will hold stocks of customers.

Anya (2005) has explained four reasons to have the stock, namely the economies of scale, balancing supply and demand, protection from uncertainties and a buffer interface. The researcher believes that, the inventory is a huge waste because the inventory will lead to increase in the final cost and profit reduction. The key elements of the inventory cost reduction from the researcher's perspective include right suppliers, production in small batches, Kanban and purchasing contracts, and thus refer to the research gap, which is, the inventory in the mentioned factory reflects the inability to produce the right products, which results a negative effect on the quality. 


\section{AIM AND OBJECTIVE}

The main aim is to investigate the availability of inventory management's main keys in mixing and mobilization oil factory in Libya, and prove the positive effect of inventory Management on reducing storage cost.

\section{STUDY QUESTIONS}

1- Is there a good level of inventory management in mixing and mobilization oil factory in Libya

2- Is there relationship between inventory management and storage cost reduction

\section{STUDY HYPOTHESIS}

There is a significant relationship between IM and storage cost.

\section{STUDY POPULATION}

The population includes the majority of the workers in mixing and mobilization oil factory in Libya. It includes some of managers and workers in the selected factory, about 150 copies of the questionnaire were distributed. The sample includes heads of departments, management, managers, control managers, finance employees, engineering, factory operators (workers), and workers in other departments, such as warehouses, computer, accounting and etc.

\section{STUDY DESIGN}

The argument of this paper is that, the existence of a good inventory management is fundamental towards sustainable development. The literature review will be an important part of this research as well as in any academic research, which will focus on many different journals articles and books in this area of research. Also collecting information from the internet to know the new changes in this topic will be very helpful. This study important because, it focuses on the methods and ways to minimize the storage cost, which in turn will decrease the production cost, also, supports the productions of Libya, and increase its ability to compete in the global market. In addition to; this study will provide information to invite the industrial sector in Libya to apply and accommodate a good IM, once they can provide the essential requirements, plus it will ascertain the disadvantage of the IM that are present in the industrial sector in Libya on the production cost specially, storage cost. Finally, The study will encourage the researcher in Libya research institutes into care and consider this area as an important research area that should improve the economy of Libya in general.

In order to provide a more comprehensive viewpoint about this topic, this study; used many different types of analysing, such as: Mean, which is used to describe the types of non-financial performance measurements, according to their importance for measurement and evaluation purposes. Standard deviation, which is used to establish the extent to which the variable values that, differs from the mean, and using a simple linear regression to know if there is a relationship between the research variables. In addition to; the study was based on an academic and theoretical literature regarding the role that inventory management play in reducing storage cost.

\subsection{Supplier}

One of the critical success keys of the inventory management is the ability to acquire quality materials at the right time and with the right quantity through the right suppliers (Shahin, 2012).

Reduce storage cost is based on choosing a few numbers of trusted suppliers, who have the ability to deliver the needed material in small batches in one day or less as scheduled, because the application of new production systems makes the company sensitive to any delay in receiving the needed materials at the needed time (Cheng, 2011; Gupta, 2011) .

Managing inventory depended on the accuracy of everything that is related to the production. Controlling must start from the material purchasing that depends on reliable suppliers and long term contracts for planning, production lines, which will be an automated design to workers who are responsible for everything, from examining manufacturing, solving 
quantitative problems, and improving the manufacturing flow-lines (Kaneko \& Nojiri, 2008; Sandamayake, Gjoduoza\& Proverbs, 2008) .

Suppliers in the short term have the ability to increase prices and limit quality, which has a strong impact on the conditions of negotiating power. However, in long term contracts, it has become important clients to the supplier, which in turn will increase quality improving and decrease prices (Bloomberg, Lemay\& Hanna, 2002; Momiwand \& Shahin, 2012).

Under the new manufacturing's operating condition, buyer-supplier relation is built on a high degree of mutual trust and openness; both the buyer and supplier must share information, and also, protect its confidentiality (Li \& Yang, 2009; Robert \& Donhauser, 2009) .

\subsection{Small batches}

Producing in small batches is the main key that leads many factories to reduce the inventory level and cost, because all administrative expenses and transportation will be reduced to the lowest level (Kumar, 2010).

In the new production system, it is usual to produce production with a high ability to make the required changes, because producing in small batches make moving from batch to another in short time easy, which provides more flexibility to achieve feedback quickly (Kumar\& Sampath, 2012; Obermaier et al., 2009) .

There are many advantages that could be achieved when producing in small quantities, such as benefitting from the places that are used as warehouses, decrease the inventory and machine problems, chance to benefit from the quantity discount when buying large quantities of raw materials in the long term (Ballou, 2004; Broyles et al., 2006)

\subsection{Kanban}

Kanban forms part of the steps that are necessary to identify the products among a series of operations, and its help in linking the different production process. It helps to meet the input time and customer delivery deadline requirements, and to control the production processes to avoid the overstock inventory through planning and scheduling everything, starting from material purchasing to the sales deliveries (Gautam, Kumar \& Singh, 2012; Kniberg, 2009) .

Kanban is a system of continuous supply of component parts and supplies, so that the workers have what they need, where they need and when they need. The word "Kan" means "visual" in Japanese and the word "ban" means "card", so "Kanban" refers to visual cards. It is an information system that is used to controlling the number of parts to be produced in every process (Hao\& Weiming, 2008; Sugimori et al., 2007)

The most common of Kanban is the withdrawal Kanban, A Kanban supplier is another type of Kanban that is used between the supplier and the manufacturer, in order to achieve the best delivery level (Jodlbauer \& Tluber, 2008) .

According to Kniberg (2009), the benefits of Kanban are to reduce inventory and product obsolescence, reduce waste and scarp, provides flexibility in production, increase output, reduce total cost of preventing over production, develop flexible work station, minimize wait time and logistics cost, reduce stock levels and overhead cost, safe sources by streamlining production, and reduce inventory cost .

\subsection{Purchasing contracts}

Even though there are many different types of contracts, the name and the title of contracts do not affect the content of contract. Under one title, there can be different kinds of contracts. There is no legislation concerning the different types of contracts. All contracts are dealt with under the same legislation form (Thurman, 2007) .

The benefits of contracts are to decrease the quantity orders, lessen paper work and entitlement to the quantity discount, that are achieved through big order quantity, clear delivery schedules, continuous stream of material or goods from the supplier to the buyer, shifting the cost of warehousing to the supplier, deliver small single batches (Ballou, 2004; Kindary, 2010) . 


\section{THE DEVELOPMENT OF THE THEORETICAL CONCEPTUAL MODEL}

A comprehensive theoretical framework linking IM with customer services and production improvement will be presented according to the theory of constraint. The theory of constraints (TOC) is a system-management philosophy developed by Eliyahu M. Goldratt in the early 1980s. The fundamental thesis of TOC is that constraints establish the limits of performance for any system. Most organizations contain only a few core constraints. TOC advocates suggest that managers should focus on effectively managing the capacity and capability of these constraints if they are to improve the performance of their organization (Cox \& Spencer, 1998). TOC challenges managers to rethink some of their fundamental assumptions about how to achieve the goals of their organizations, about what they consider productive actions, and about the real purpose of cost management. TOC focuses on understanding and managing the constraints that stand between an organization and the attainment of its goals, and emphasizes the need to add new models to the information toolkit grows (Mcmulen, 1998). It is providing unique insights and focus into the ongoing challenges of identifying the products and services that will maximize customer value-added and organizational profitability (Ruhl, 1997). Based on above overview and the theory of constraints, the main elements of inventory management classified as shown in the following figure:

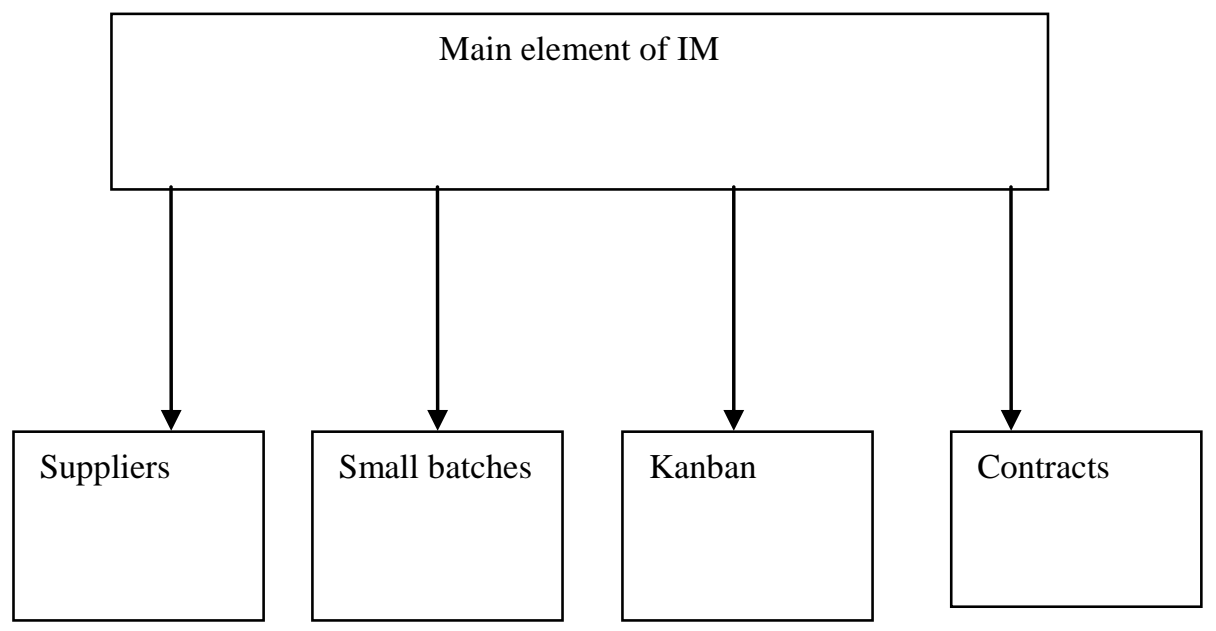

\section{DATA ANALYSIS}

The main aim of this part is to present the analysis of the overall result that related to the study objectives, and testing the main hypothesis using many different analyses.

\subsection{Statistical Analysis}

Table 1 shows the mean, frequency distribution and T- test of the research sample respondents about the availability of the IM, which is inventory management in the target factory in Libya.

Based on the mean of the items that about the inventory management, as presented in Table 1, the item that concerned respondents the most was that the factory has a good relationship with suppliers, $\mathrm{M}=3.55, \mathrm{Std}=0.956, \mathrm{P}<0.05$ about $63.1 \%$ of the respondents agreed about this item. That reflects the ability to select the right suppliers.

This supported the study conducted by Lie\& Yang (2009); Momiwand\& Shahin (2012) in which the researchers wrote that, the buyer-supplier relation is built on a high degree of mutual trust and openness; both the buyer and supplier must share information and also protect its confidentiality. When entering into this type of relationship, it is important that the company select suppliers that have consistently exhibited high levels of quality and delivery reliability.

This is followed by the completed products delivered after completion to eliminate warehousing $\mathrm{M}=3.29, \mathrm{Std}=1$. 076, $\mathrm{P}$ $<0.05$, which refers to the law of warehouses for complete products, if found. 
This is followed by the item, the purchasing contracts are adopted, M=3. 27, Std $=1.076$. This means that the factories need to have a huge of inventory to avoid the production interruption, because the materials imports from abroad, which reflects the real problem that the storage cost faced in this factory.

Table-1: Frequency distribution and T- test of the research sample respondents about the availability of the IM

\begin{tabular}{|l|l|l|l|l|l|l|l|l|}
\hline No & Rank & Item & Agree & Disagree & Mean & SD & T-test & P-value \\
\hline 1 & 1 & $\begin{array}{l}\text { The factory has good relation with } \\
\text { suppliers }\end{array}$ & $63.1 \%$ & $14.2 \%$ & 3.55 & 0.956 & 9.115 & $0.000^{*}$ \\
\hline 2 & 5 & $\begin{array}{l}\text { The factory adopts the modern } \\
\text { system Kanban }\end{array}$ & $29.2 \%$ & $55.9 \%$ & 2.68 & 1.081 & -4.592 & $0.000^{*}$ \\
\hline 3 & 2 & $\begin{array}{l}\text { The completed products are } \\
\text { delivered to the consumers } \\
\text { immediately }\end{array}$ & $53.0 \%$ & $25.9 \%$ & 3.29 & 1.076 & 4.256 & $0.000^{*}$ \\
\hline 4 & 6 & $\begin{array}{l}\text { The small batches and evaluating } \\
\text { process are adopted }\end{array}$ & $22.2 \%$ & $56.5 \%$ & 2.61 & 0.964 & -6.335 & $0.000^{*}$ \\
\hline 5 & 3 & $\begin{array}{l}\text { The factory makes purchasing } \\
\text { contracts }\end{array}$ & $55.5 \%$ & $29.2 \%$ & 3.27 & 1.075 & 3.906 & $0.000^{*}$ \\
\hline 6 & 4 & $\begin{array}{l}\text { The inventory control is available } \\
\text { such as order predetermined } \\
\text { quantity when the inventory } \\
\text { reaches a predetermined lower } \\
\text { limit }\end{array}$ & $53.9 \%$ & $31.6 \%$ & 3.21 & 1.096 & 3.076 & $0.002^{*}$ \\
\hline
\end{tabular}

Looking at this finding, it is sufficient to say that the research confirmed that the warehouses of material is the main reason for having a huge inventory, and that supports the research motivations. However, the lowest mean are to the items that adopt Kanban, produce in a small batches, which indicates the necessity of having an immediate reaction to provide these important keys to implement this system in the company. This argued with Kumar 2010 who ascertains the importance of adopting small batches, and the opinion of Hao\& Weiming (2008) who wrote about the importance of Kanban.

Finally, the overall mean of this element is $\mathrm{M}=3.17$ with $\mathrm{Std}=0.540, \mathrm{P}<0.05$, which reflects the lack of the knowledge about IM and its necessary elements, because the majority of respondents give the answer "somewhat agree" about the availability of IM. This result indicates that there is a good level of inventory management in the target factory in Libya. These findings agreed with Alan (2008); and Vedran et al., (2009) who explained that neglecting the importance of the inventory can lead to the close down of the company, especially if the production of factories are not well managed in order to meet the customers' needs or desires. The company will grind to the halt. The stock of an item must be reasonable, meaning that it should be not too much or too little. The company should be in a position to meet customer's demand, in terms of quantity and quality.

\subsection{Testing the Study- Hypothesis H1}

There is a statistical significant relationship at 0.05 levels between the inventory management as an independent variable, and storage cost reduction as the dependent variable.

To validate this hypothesis, it's necessary to test the following statistical hypotheses:

\section{Null Hypothesis Ho}

There is no statistical significant relationship at 0.05 levels between the inventory management as an independent variable, and storage cost reduction as the dependent variable $(\mathrm{H} 0: \mathrm{B} 1=0)$. 


\section{Alternative Hypothesis H1}

There is a statistical significant relationship at 0.05 levels between the inventory management as an independent variable, and storage cost reduction as the dependent variable $(\mathrm{H} 1: \mathrm{BI} \neq 0)$.

The simple linear regression has used to verify this hypothesis, and know the relationship between the IM as an independent and variable storage cost reduction as the dependent variable.

Table 2 shows simple linear regression to test the relationship between the inventory management and storage cost reduction.

Table 2: Simple Linear Regression Test

\begin{tabular}{|c|c|c|c|c|}
\hline Independent variable & $\mathrm{R}$ & $\mathrm{R}$ Square & F- Test & P-Value \\
\hline IM & 0.942 & 0.242 & 78.231 & 0.000 \\
\hline
\end{tabular}

Significance at 0.05 levels

Due to the finding of this table, $\mathrm{R}=0.942, \mathrm{~F}=78.231, \mathrm{p}<0.05$ which is significant. This result can be interpreted as a meaning that, there is a relationship between the inventory management as an independent variable, and storage cost reduction as the dependent variable. Thus, the null hypothesis is rejected $(\mathrm{H} 0$ : $\mathrm{B} 1=0)$ and the alternative hypothesis is accepted $(\mathrm{H} 1: \mathrm{B} 1 \neq 0)$ on the basis that there is a significant relationship between the IM and SC. This good indicator that the targets factories can benefit of inventory management in reducing the products cost. Also, the table shows that the value of $\mathrm{R}^{2}=0.242$ which represents the change in an independent variable, inventory management explains $24.2 \%$ of the change in the dependent variable storage cost reduction.

This finding are in line with many studies, which pointed that the potential benefits of having a good inventory management are: low inventory carrying cost, quality, minimal expediting and order release work, simplified communication and receiving activities, productivity by reduced rework, reduce inspection, reduce parts- related delays, increase of customer satisfaction because of better quality and delivery reliability, improve profits through a better management of material resulting from lower inventory levels and reduce warehouse requirements, improve relation with internal customers, improve communication links with major suppliers resulting in a more productive relationship and improve customer delivery reliability (Coyle, Bradi \& Langley, 2003; Broyles et al., 2006 ).

\section{DISCUSSION AND ONCLUSION}

The main purpose of this study was to identify the key elements that help IM to reduce storage cost in the mixing and mobilization oil factory in Libya. Thus, this study suggested that the inventory management is the main factor that affects the storage cost, and the keys that necessary to reduce the level of inventory are to choose the right suppliers, use Kanban, produce in small batches and use purchasing contracts. These keys are essential for a successful cost reduction.

Keeping inventory is not acceptable in new manufacturing systems; it must be reduced to a minimum where the required quantities are sufficient for delivered, that will reduce the other cost to the lowest possible level. The philosophy of new methods system is that inventory should be as less as possible, which make all costs that related to inventory that unnecessary to production steps is incurring costs because this view how inventory related to accounting system and management.

There are many advantage could be achieved when the inventory is minimized for instance, benefit from the places that used to warehouses, decrease the inventory and machine problems, chance to benefit from quantity discount when buying a large quantities of raw materials in the long term such as, increase productivity and the rate of return investment and inventory turnover, produce the demand production without surplus, eliminate all kind of wasting time, no defective production, reduce inventory to minimum, eliminate unnecessary activities.

The inventory considers the main problem in Libya, because the company must keep an inventory to avoid the problem of inventory shortage. Therefore, the main and necessary step to avoid this problem in the Libyan environment is starting from choosing the right suppliers with advanced technological capabilities and unique design skills. The suppliers' ability to deliver high quality materials in the need time refers to desired level of quality, which in turn impact the customer's satisfaction. 
Finally, based on the extensive review of related literatures on the subject matter, it has come to the light that the efficient use of the technology plays an important role in reducing the cost to the lowest level and increases the competitiveness to the highest possible level through such means like the zero inventory level.

In conclusion, this research suggested that the IM is the mainly factor that most affects the storage cost, and the keys that necessary to reduce the level of inventory are to choose the right suppliers, use Kanban, produce in small batches and use purchasing contracts.

\section{REFERENCES}

- Apod, N. N. (2001). Operation Management, General Institute Management, Researches Centres. Elriath Suadi Arabi.

- Alan, C. R. (2008). Inventory Improvement \& Financial Performance. International Journal of Production Economics, 115(2), pp.581- 593.

- Anya, M. F. M. (2005), Inventory Management as Determinant for Improvement of Customer Service, University of Pretoria.

- Ballou, R. H. (2004). Business logistics/ Supply Chain Management. Planning Organization and Controlling the Supply Chain. 5 th Edition. Pearson Pren Hall. USA.

- Broyles, D., Beims, J., Franco, J., Bergman, M., (2006). Just In Time Inventory Management Strategy Overview: Kansas State University. USA.

- $\quad$ Bloomberg, D. G., Lemay, S. \& Hanna, J. B. (2002). Logistics Prentice Hall. New Jersey. USA.

- Chase, R. B., Jacobs, F. R \& Aquilano, N. J. (2004). Operation Management for Competitive Advantage. 10 th Edition. International Edition.M C Graw Hill.N Y.

- Cheng, L. C. (2011). Logistics Strategies to Facilitate Long Distance, Just In Time Supply Chain System. University of Huston, United States of America.

- Cox, J.F., \& Spencer, M ( 1998). .The Constraints Management Handbook. Boca Raton, FL: St.Lucie Press.

- Gautam, R., Kumar, S., Singh, S. (2012). Kaizen Implementation in An Industry in India- A Case Study. IJRMET, 2(10).

- Gupta, A. K. (2011). A conceptual JIT Model of Service Quality. International Journal of Engineering Science and Technology, 3. (3).pp. 2214-2227.

- Hao, Q. I. \& Weiming, S. (2008). Implementing hybrid Simulation Model for Kanban- Based Material Handling System, Robotics and computer. Integrated Manufacturing, 24(5).

- Jodlbauer, H.J. \& Tluber, A. ( 2008). Service Level Performance of MRP, Kanban, Cownwip and DBR due to Parameter Stability and Environ Mental Robustness.International Journal of Production research, 46 ( 8).

- Josep, T. A. (2009). Firms's Stock Market Flotation: Effects on Inventory Policy. International Journal of Production Economics, 118.

- Kaneko, J., Nojiri, W. (2008). The Logistics of Just In Time between Parts Suppliers and Car Assemblers in Japan. Journal of Transport Geography, 16. (3), pp. 155-173. Japan.

- Kindary, K. (2010). The Logistics Role in Improve the Organization Competition: Study Case, Oras Organization. PhD Thesis:University of AlhajKhader. Batna. Aljera.

- Kniberg, H. (2009). Kanban Fcscrum, Scrps. Version 1.1 http:/ www.infg.com/minubooks/kanban-scrumminibook.

- $\quad$ Kumar. V. 2010. JIT Quality Management, Concepts and Implications in Indian Context. International Journal of Engineering Science and Technology, 2 (1), pp40-50. India.

- Kumar, B. S \& Sampath, V. R. (2012). Garment Manufacturing through Lean Initiative. an empirical study on WIP Fluctuation in T- shirt production Unit. European Journal of Scientific Research, 73 (2), pp. 235 - 244.

- Krisztina, D. \& Matyusz, Z. (2010). The Impact of Lean Practices on Inventory Turnover. International Journal of Production Economics. J.IJPE, 133( 1), pp. 154-163.

- Li, B. \& Yang, C. (2009) . Production Logistics System Based on Hybrid Push/ Pull Control. Strategy in Making- To- Order Environments. International Journal of Innovative Computing, Information and Control, 5 ( 5).pp 1345-1350.

- Mahmod, S. (2011). Material Handling. Promote a Culture of Leadership in the Palestinian society.

- McMullen, T ( 1998). Introduction to the Theory of Constraints (TOC) Management System. Boca Raton, FL: St. Lucie Press.

- Monden, Y. (1983). Toyota Production System. Institute of Industrial Engineering. Athanta, GA.

- Momiwand, A., Shahin, A. (2012). Lead Time Improvement by Supplier Relation Management with a Case Study in Pompaj Company. World Applied Sciences Journal,16 (5). pp759-768. 
- Obamiro, J. K. ( 2009). Exploring the Relationships Between Just In Time Technique and Manufacturing Performance: Empirical Evidence From Selected Nigerian Firms. Economic, Social, Political and cultural Problems of the Future Society(10).pp 165- 176.

- Sandamayake, Y., Gjoduoza, C.F. \& Proverbs, D.G. (2008). A Systematic Modelling and Simulation Approach for JIT Performance Optimization, Robotics and Computer. Integrated Manufacturing, 24 (6).

- Sugimori, Y. A., Kusunokia, K., Cho, F. A \& Uchikawa, S. (2007).Toyota Production System and Kanban System Materialization of Just-In-Time and Respect-for-Human System. International Journal of Production Research, 15(6), pp 553-564.

- Shahin, A. (2012). Lead Time Improvement by Supplier Relation MangementWith A Case Study in Pompaj Company. World Applied Sciences Journal. Vol 16 (5).

- Thurman, R. (2007). Purchasing Contracts in the Textile Industry: How Can Purchasing Contracts Decrease Subcontracts Risks and Reclamations in Textile Industry Company Instructor. Marita Toumala.

- Vedran, C., Hameri, A. \& Weiss, L. A. (2009). On the Relationship between Inventory and Financial Performance in Manufacturing Companies. International Journal of Operating \& Production Management, 29 (8): $P$ 789- 806.

- $\quad$ Robert, O. \& Donhauser, A. (2009). Disaggregate and Aggregate Inventory to Sales Rations Over Time: The Case of German Corporations 1993- 2005. Logistics Research, 1 (2).

- Ruhl, J ( 1997). Applying the Theory of Constraints to Enhance Profitability."Handbook of Cost Management. New York: Warren, Gorham and Lamont, pp. F5-1-F5-41. 